\title{
REVIEW
}

\section{A global perspective on vasoactive agents in shock}

\author{
Djillali Annane ${ }^{1 *}$, Lamia Ouanes-Besbes² ${ }^{2}$ Daniel de Backer ${ }^{3}$, Bin DU ${ }^{4}$, Anthony C. Gordon ${ }^{5}$, Glenn Hernández ${ }^{6}$, \\ Keith M. Olsen ${ }^{7}$, Tiffany M. Osborn ${ }^{8}$, Sandra Peake ${ }^{9,10}$, James A. Russell ${ }^{11}$ and Sergio Zanotti Cavazzoni ${ }^{12}$
}

C 2018 Springer-Verlag GmbH Germany, part of Springer Nature and ESICM

\begin{abstract}
Purpose: We set out to summarize the current knowledge on vasoactive drugs and their use in the management of shock to inform physicians' practices.

Methods: This is a narrative review by a multidisciplinary, multinational—from six continents—-panel of experts including physicians, a pharmacist, trialists, and scientists.

Results and conclusions: Vasoactive drugs are an essential part of shock management. Catecholamines are the most commonly used vasoactive agents in the intensive care unit, and among them norepinephrine is the first-line therapy in most clinical conditions. Inotropes are indicated when myocardial function is depressed and dobutamine remains the first-line therapy. Vasoactive drugs have a narrow therapeutic spectrum and expose the patients to potentially lethal complications. Thus, these agents require precise therapeutic targets, close monitoring with titration to the minimal efficacious dose and should be weaned as promptly as possible. Moreover, the use of vasoactive drugs in shock requires an individualized approach. Vasopressin and possibly angiotensin II may be useful owing to their norepinephrine-sparing effects.
\end{abstract}

Keywords: Shock, Cardiovascular system, Adrenergic agonists, Clinical trials, Practice guidelines

\section{Introduction}

Acute illnesses are often characterized by a loss in cardiovascular homeostasis. Underlying mechanisms may include multiple factors altering blood volume (actual or effective), cardiac (diastolic and/or systolic) function or the vessels (large vessels and/or microvasculature). Vasopressors and inotropes are vasoactive drugs that have been developed to act on the vessels and the heart. In practice, a number of drugs are available with heterogeneous mechanisms of action and varying benefit to risk balance. This narrative

\footnotetext{
${ }^{*}$ Correspondence: Djillali.annane@aphp.fr

${ }^{1}$ General ICU, Raymond Poincaré Hospital (APHP), School of Medicine

Simone Veil U1173 Laboratory of Infection and Inflammation (University of Versailles SQY, University Paris Saclay/INSERM), CRICS-TRIGERSEP

Network (F-CRIN), 104 boulevard Raymond Poincaré, 92380 Garches, France

Full author information is available at the end of the article

All authors have equally contributed to this manuscript.
}

review provides a summary of current knowledge about vasopressors and inotropes to guide intensive care physicians' practices when managing patients with shock.

\section{Pharmacological basis Catecholamines}

Vasoactive agents are classified into sympathomimetics, vasopressin analogues, and angiotensin II. Catecholamines are further subdivided in categories of indirect, mixed-acting, and direct acting. Only the direct acting agents have a role in shock. Direct agents are further delineated by their selective nature (e.g., dobutamine, phenylephrine) or non-selective activity (e.g., epinephrine, norepinephrine) on $\alpha_{1}, \alpha_{2}, \beta_{1}, \beta_{2}$, and $\beta_{3}$ receptors [1]. Catecholamines are most often linked to clinical improvement in shock states $[1,2]$. Catecholamines act by stimulation of either $\alpha$ or $\beta$ receptors, exerting excitatory action on smooth muscle and resulting in vasoconstrictive or

\section{至 Springer}


vasodilatory effects in skin, kidney, and lung. Intravenous (IV) administration of epinephrine or norepinephrine results in increasing blood pressure with increasing dose. The rise in blood pressure is due to vasoconstriction and $\beta$ receptor stimulation. $\beta$-stimulation directly increases inotropy and heart rate. Although receptor responses have classically been presented as linear, all responses follow a sigmoidal type curve resulting in a pharmacological response to increasing doses followed by a plateau affect. Dopamine receptors include at least five subtypes that are broadly distributed in the central nervous system, in pulmonary and systemic blood vessels, cardiac tissues and the kidneys [1]. The impact on receptors provides the pharmacologic basis for catecholamine therapy in shock. Clinicians should also be aware of their effects on glycogenolysis in the liver and smooth muscle, free fatty acid release from adipose tissue, modulation of insulin release and uptake, immune modulation, and psychomotor activity in the central nervous system.

\section{Vasopressin and analogues}

Vasopressin is a potent nonapeptide vasopressor hormone released by the posterior pituitary gland in response to hypotension and hypernatremia [3]. Vasopressin stimulates a family of receptors-V1a (vasoconstriction), V1b (ACTH release), V2 (anti-diuretic effects), oxytocin (vasodilator) and purinergic receptors (of limited relevance to septic shock). Vasopressin paradoxically induces synthesis of nitric oxide (NO) [4]. NO may limit vasopressin's vasoconstriction, while preserving renal perfusion [5]. However, it may also contribute to vasopressin/NO-induced cardiac depression. Notably, V1a-receptor activation of vascular smooth muscle induced vasoconstriction is catecholamine-independent and may explain why vasopressin complements norepinephrine in septic shock. The main rationale for vasopressin infusion in septic shock is wellestablished. Vasopressin deficiency in early septic shock [6] is due to depletion of vasopressin stores and inadequate synthesis and release from the hypothalamic-pituitary axis. Low dose vasopressin infusion of 0.01-0.04 units/ min, increased blood pressure and decreased norepinephrine requirements [6-10]. Vasopressin deficiency and its anti-diuretic effects only become apparent later, during septic shock recovery with about $60 \%$ of patients having inadequate vasopressin responses to an osmotic challenge 5 days post recovery from septic shock [11]. Highly selective V1a agonists could have better effects in septic shock than vasopressin because of the narrow focus on the V1a receptor [12]. In addition to minimizing V2 anti-diuresis, less or no von Willebrand factor release is reported (V2 mediated) and there is some evidence in animal models of less vascular leak with V1a agonists compared to vasopressin [13-16]. The highly selective V1a agonist selepressin decreased lung oedema and fluid balance more than vasopressin and control groups with concomitant mitigation of decreased plasma total protein concentration and oncotic pressure [16].

\section{Calcium sensitizers}

Calcium sensitizers produce their inotropic effect by sensitizing the myocardium to existing calcium, rather than increasing intracellular concentrations. This has the advantage of producing increased myocardial contraction (inotropy) without the same increases in oxygen demand as other inotropes. Furthermore, as calcium levels fall in diastole, calcium sensitizers do not impair relaxation in the same way as other inotropes.

Levosimendan is the only calcium sensitizer in clinical use [17]. Opening of ATP-sensitive potassium channels in vascular smooth muscle results in vasodilatation and through actions in the mitochondria of cardiomyocytes, it is reported as cardioprotective in ischaemic episodes. At higher doses it also exhibits phosphodiesterase III inhibitor effects. Although the parent drug has a short half-life of about $1 \mathrm{~h}$, an active metabolite, OR1896, has a long half-life and therefore a 24-h infusion of levosimendan can have haemodynamic effects for about 1 week.

\section{Selective beta- 1 antagonists}

Although sympathetic stimulation is an appropriate physiological response to sepsis there is evidence that if excessive this can become pathological [18]. Both high levels of circulating catecholamines and tachycardia have been associated with increased mortality in septic shock [19]. Although myocardial dysfunction is common in sepsis, short-acting $\beta 1$ antagonists may have beneficial cardiovascular effects through slowing heart rate, improving diastolic function and coronary perfusion [20]. Esmolol is a cardioselective $\beta_{1}$ receptor antagonist with rapid onset and very short duration of action [21]. Landiolol is an ultra-short acting $\beta$ blocker about eight times more selective for the $\beta 1$ receptor than esmolol [22].

\section{Others}

Historically, angiotensin was recognized as a potent vasoconstrictor [23]. Angiotensin increases blood pressure mainly by stimulating NADH/NADPH membrane bound oxidase with subsequent oxygen production by vascular smooth muscles [24]. Recently, a synthetic human angiotensin II was shown to act synergistically with norepinephrine to increase blood pressure in patients with vasodilator shock [25]. Methylene blue and non-selective inhibitors of NO synthase induced vasoconstriction by modulating endothelial vascular relaxation, and phosphodiesterase type III inhibitors exert inotropic effects 
and vasodilation by modulating cyclic AMP metabolism [26].

\section{Cardiovascular effects}

Effects of catecholamines on the cardiovascular system are summarized in Fig. 1.

\section{Effects on the heart \\ Catecholamines}

Vasoactive agents are utilized in shock with the intent of counteracting vasoplegia, myocardial depression or a combination of both. Potential benefits are balanced against the possible negative impact on cardiac output (CO), myocardial oxygen consumption, myocardial perfusion and cardiac rhythm. Norepinephrine effects on cardiac function and $\mathrm{CO}$ are inconsistent and time-dependent [27-29], which may be related to baseline cardiovascular state, ventriculo-arterial coupling [30] and potential unmasking of myocardial depression with increased afterload [31]. Usually the direct positive chronotropic effects of norepinephrine are counterbalanced by the vagal reflex activity of the increased blood pressure [1]. Norepinephrine also increases stroke volume and coronary blood flow partly by stimulating coronary vessel $\beta_{2}$-receptors [32]. These potential positive effects of norepinephrine on cardiac function are often transient. Epinephrine is a much more powerful stimulant of cardiac function than norepinephrine, i.e., has more $\beta$-adrenergic effects. Epinephrine accelerates heart rate, improves cardiac conduction, stimulates the rate of relaxation, and reinforces systolic efficiency, with subsequent increase in $\mathrm{CO}$ at the cost of dramatic increase in cardiac work and oxygen consumption [1]. Epinephrine does not shorten diastole as a result of increased end diastolic time by shortening systole, decreased the resistance of the myocardium during diastole, accelerating relaxation after contraction, or increasing filling pressure [1]. Epinephrine may be associated with a higher risk of tachycardia and arrhythmias than norepinephrine [29, 33, 34]. Dopamine acts through several receptors; at infusion rates of $2-15 \mu \mathrm{g} / \mathrm{kg} / \mathrm{min}$, this drug stimulates $\beta_{1}$-receptors with increased myocardial contractility at the cost of tachycardia and increased risk of arrhythmias $[2,26,35,36]$. The clinical effects in shock, of stimulation

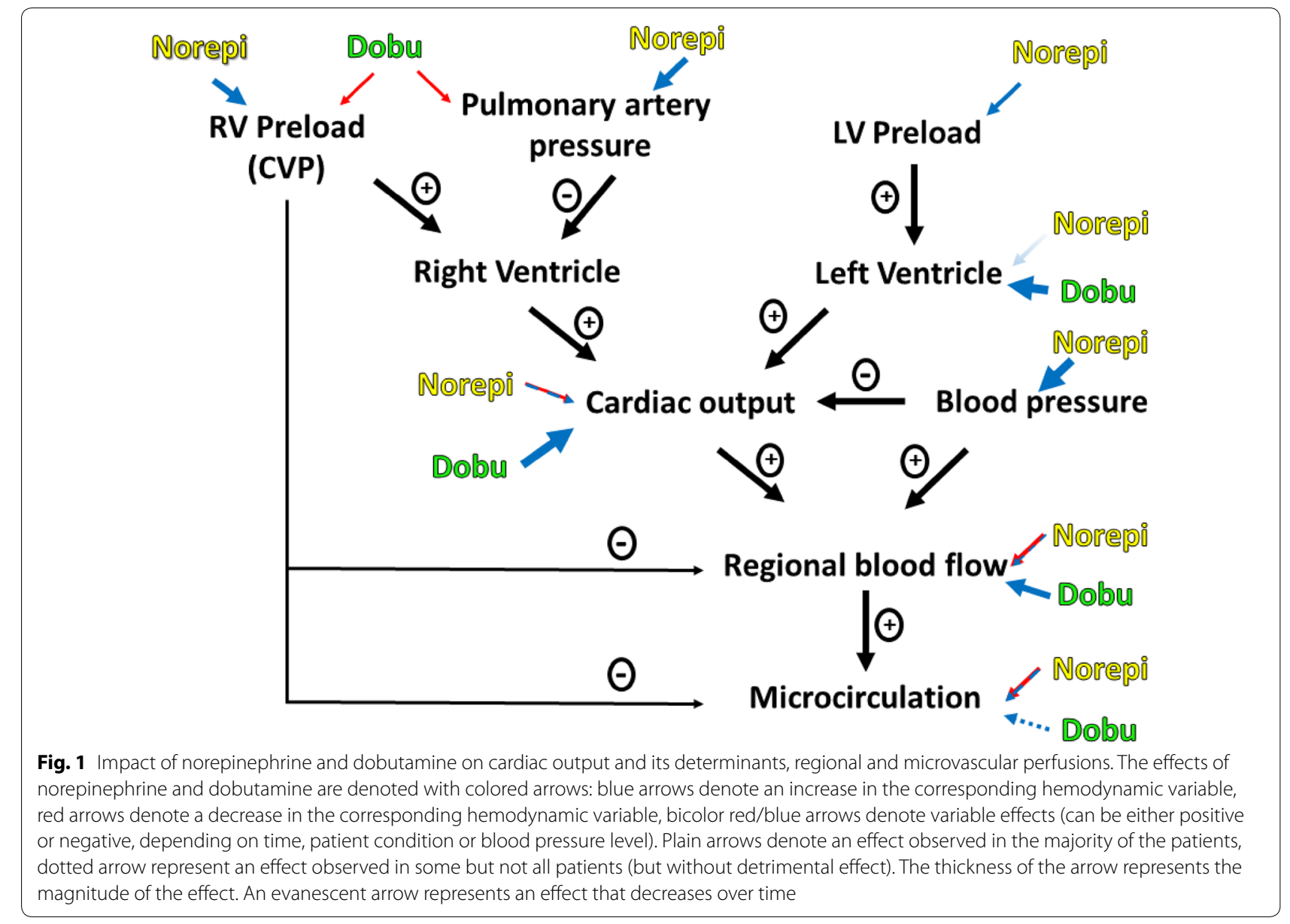


of cardiac dopamine receptors remain unclear. Phenylephrine is a pure $\alpha$-agonist, which increases afterload and reduces heart rate and $\mathrm{CO}$ [37].

\section{Vasopressin and analogues}

Vasopressin and its analogues may impair cardiac contractility via vasopressin V1a receptor-mediated decreased $\beta$-adrenergic receptor sensitivity [38]. Likewise, angiotensin may impair $\mathrm{CO}$ via increased afterload.

\section{Inotropes}

Inotropes are used in patients with myocardial depression, to improve $\mathrm{CO}$ through enhanced cardiac myofibril contractility [39]. Although dobutamine may initially decrease vascular tone, MAP is usually improved with the increased $\mathrm{CO}$ except in condition of low systemic vascular resistance. Phosphodiesterase III inhibitors also increase myocardial contractility (possibly synergistically with dobutamine) but are often associated with hypotension and arrhythmias. While these agents are potentially interesting for right ventricular failure due to their effects on right ventricular afterload, great caution should be observed in preserving coronary perfusion. Levosimendan increases contractility and $\mathrm{CO}$ with minimal tachycardia and without increasing myocardial oxygen consumption but often with significant decrease in MAP (especially with loading dose). In cardiogenic shock, as compared to dobutamine, levosimendan may result in higher CO and lower cardiac preload [40].

\section{Selective $\beta_{1}$-antagonists}

Administration of short-acting selective $\beta_{1}$-antagonists increased systolic function and left ventricle end-diastolic volume, reduced myocardial oxygen consumption, and restored cardiac variability during both experimental sepsis and heart failure [20]. These drugs showed substantial improvement in stroke volume and $\mathrm{CO}$ in patients with severe septic shock and tachycardia [41].

\section{Effects on systemic and pulmonary circulations}

Norepinephrine and epinephrine are equipotent with regard to their effects on systemic blood pressure and systemic vascular resistance [33, 34]. Low dose epinephrine may lower systemic blood pressure, via activation of vascular $\beta_{2}$ adrenergic receptors, an effect not seen with norepinephrine [1]. Norepinephrine and epinephrine similarly increase pulmonary artery pressure and pulmonary vascular resistance with little effects on pulmonary capillary wedge pressure [42]. Norepinephrine also decreases preload dependency [43] possibly by increasing venous return via a shift of unstressed to stressed volume, with subsequent transient increase in $\mathrm{CO}$ [44]. High dose dopamine $(10-20 \mu \mathrm{g} / \mathrm{kg} / \mathrm{min})$ stimulates $\alpha$-adrenergic receptors and increase systemic vascular resistance. However, clinically it increases MAP through increased $\mathrm{CO}$ with little to no peripheral vasoconstriction $[2,35,36]$. Dobutamine decreases systemic and pulmonary vascular resistance with little change in systemic blood pressure owing to increased $\mathrm{CO}$. Vasopressin is usually used for its norepinephrine sparing effects. This drug increases afterload without pulmonary vasoconstriction [8]. Vasopressin may have beneficial effects for right heart function $[9,10]$. However, conflicting reports regarding its use as a primary agent in post-cardiac surgery vasoplegic syndrome include dysrhythmia and myocardial infarction [45-47]. In septic shock, selepressin decreased norepinephrine requirements and limited positive fluid balance [14]. This drug has been investigated in a Phase IIB/III trial which is now completed after the recruitment of 868 patients [48]. In adults with vasoplegic shock, a new synthetic human angiotensin II substantially increased systemic vascular resistance without alteration in $\mathrm{CO}$, and subsequently increased blood pressure [25]. In septic shock, infusion of levosimendan was associated with significant reduction in systemic vascular resistance necessitating increased doses of norepinephrine [49]. Interestingly, levosimendan may decrease pulmonary vascular resistance, and may improve right ventricular function when pulmonary artery pressure is high [17].

\section{Effects on regional circulation}

In general, $\beta$-adrenergic agents, phosphodiesterase III inhibitors and levosimendan increase splanchnic perfusion while $\alpha$-adrenergic agents and vasopressin have more variable effects. Several studies have shown that dobutamine usually increases splanchnic perfusion but with high individual variability $[50,51]$. The effects were observed at low doses $(5 \mu \mathrm{g} / \mathrm{kg} / \mathrm{min})$, and dose escalation did not affect splanchnic perfusion further.

Vasoactive drugs can improve splanchnic perfusion by restoring organ perfusion pressure. Pressures higher than autoregulation pressure can be either neutral or detrimental. Two factors need to be taken into account: both the nature of the agent and that dose may affect the response. At low doses, adrenergic agents have relatively similar and neutral effects; while at high doses can impair splanchnic perfusion and metabolism [52]. Similarly, vasopressin has modest effects on the splanchnic circulation at low doses but markedly impaired it at high doses [53].

Inotropic agents improve renal perfusion only in the setting of low CO. Vasoactive drugs improve renal perfusion when correcting hypotension during euvolemia. Vasopressin may have a greater impact on glomerular filtration pressure through a preferential effect on efferent arteriole, explaining the greater urine output and creatinine clearance obtained at the same blood pressure, compared to norepinephrine [10]. 
Table 1 Summary of Non-Cardiovascular Effects of Vasoactive Drugs

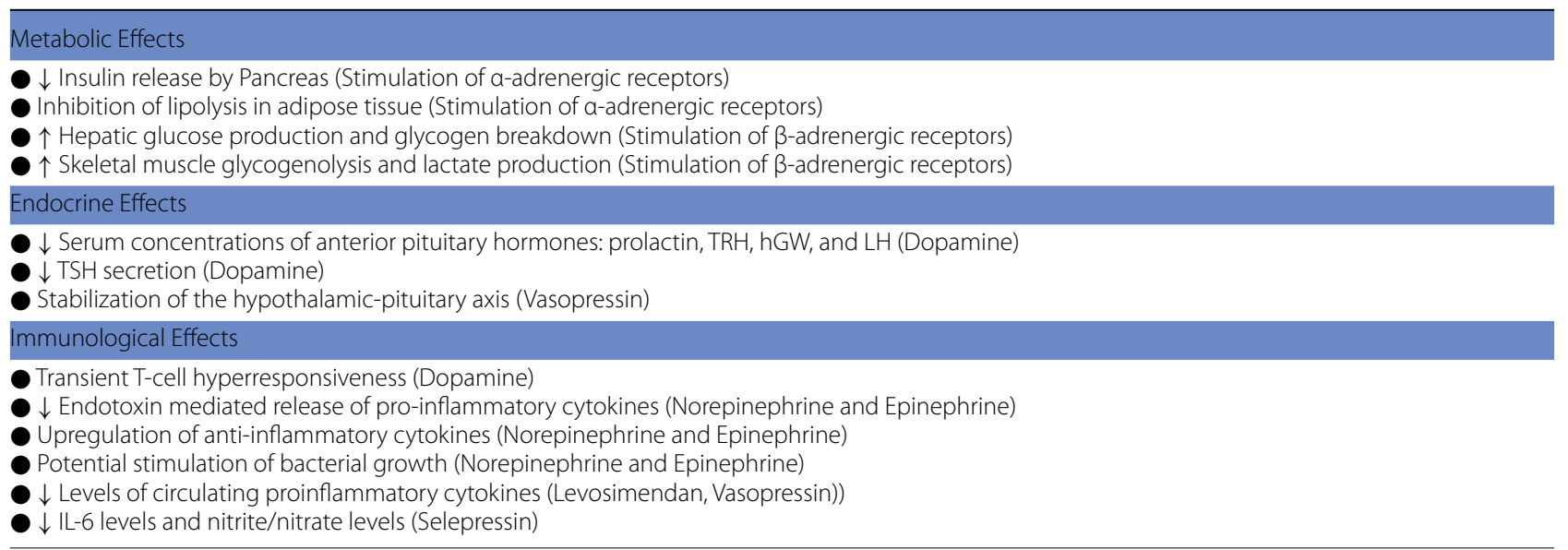

$T R H$ thyrotrophic releasing hormone, $h G W$ human growth hormone, LH luteinizing hormone, $T S H$ thyroid stimulating hormone, IL- 6 interleukin 6

\section{Effects on the microcirculation}

When mean arterial pressure decreases below an autoregulatory threshold of 60-65 $\mathrm{mm} \mathrm{Hg}$, organ perfusion becomes pressure-dependent. In this setting, increasing MAP with vasopressors might improve microcirculatory flow in severely hypotensive septic shock patients [54]. On the other hand, above the autoregulation threshold, vasopressor-induced excessive vasoconstriction could also be deleterious [55]. In septic shock, increasing MAP above $65 \mathrm{~mm} \mathrm{Hg}$ with incremental doses of norepinephrine showed considerable variations in individual responses depending on basal microcirculatory status, timing, or other factors [56-58]. Phenylephrine has detrimental effects on microvasculature perfusion in shock patients [59, 60]. Vasopressin (or analogues) has variable effects on microcirculation [61-64]. Recent studies suggest comparable effects to norepinephrine [65-67]. In clinical practice with refractory hypotension, increasing MAP with norepinephrine improves microcirculatory perfusion. Nevertheless, the optimal MAP and dose of vasoactive drug for an optimal microcirculatory perfusion are fairly variable, should be tailored to individuals and whenever possible monitored.

The microcirculatory response to dobutamine had a high individual variability, resulting in different results between trials [51, 68-70]. Dobutamine improved the microcirculation mainly in patients in whom it was severely altered via unclear mechanisms that are independent of its effects on the macro-circulation $[68,69]$. The effects of levosimendan and phosphodiesterase III inhibitors are still uncertain with beneficial effects in experimental models and scarce data in humans [71-73].

\section{Metabolic and endocrine effects Effects on metabolism}

Non-cardiovascular effects of vasoactive drugs are summarised in Table 1. Stimulation of $\alpha$-adrenergic-receptors results in reduced insulin release by $B$ cells of the pancreas, reduced pituitary function, and inhibited lipolysis in adipose tissues [1]. Stimulation of $\beta$-adrenergic receptors in the liver increases glucose production and glycogen breakdown via formation of cyclic AMP. In skeletal muscles, owing to the absence of glucose-6-phosphatase, $\beta$-adrenergic stimulation activates glycogenolysis and lactate production [74]. In practice, compared to norepinephrine, epinephrine infusion was associated with a transient, non-clinically relevant, increase in serum lactate levels and decrease in arterial $\mathrm{pH}[29,33,34]$. There is no evidence of any metabolic effects of vasopressin or its analogues, human synthetic angiotensin II, and levosimendan when administered to critically ill patients.

\section{Effects on hormones}

Dopamine decreases serum concentrations of all anterior pituitary hormones (prolactin, thyrotrophic releasing hormone, growth hormone, and luteinizing hormone) via $\mathrm{D}_{2}$ receptors in the anterior pituitary and the hypothalamic median eminence [75]. Dopamine can also induce or aggravate the low- $\mathrm{T}_{3}$ syndrome by suppressing thyroid stimulating hormone secretion and decreasing thyroxin and tri-iodo-thyroxin levels. Moreover, dopamine may suppress serum dehydroepiandrosterone sulphate, an effect mediated by low levels of prolactin or thyroid hormones. Moreover, dopamine blunts pulsatile growth hormone secretion and decreases concentrations 
of insulin-like growth factor-1, which is implicated in peripheral tissue and bone anabolism. Vasopressin modulates ACTH release by the hypothalamus-pituitary axis via $\mathrm{V} 1 \mathrm{~b}$ receptors and cortisol release by the adrenal cortex via V1a receptors [76].

\section{Immune effects}

Immune dysfunction during critical illness varies from excessive inflammatory response to immune paralysis. Sepsis may be characterized by defective antigen presentation, $T$ and $B$ cell mediated immunity, and defective Natural killer cell mediated immunity, relative increase in T-regs, activation of PD-1, decreased immunoglobulin levels, quantitative and qualitative alterations in neutrophils, hypercytokinaemia, complement consumption, and defective bacterial killing/persistence of neutrophil extracellular traps [77]. Catecholamines may aggravate sepsis associated immune paralysis [20]. Dopamine decreases serum levels of prolactin that triggers a transient $\mathrm{T}$ cell hyporesponsiveness and may reduce lymphocyte count, although decreased serum dehydroepiandrosterone may also play a role. In addition, dopamine may also inhibit the transformation of lymphocytes by mitogens. Epinephrine and norepinephrine may downregulate endotoxin induced immune cells release of proinflammatory cytokines and upregulate anti-inflammatory cytokines (e.g., IL-10). They may also stimulate bacterial growth by removal of iron from lactoferrin and transferrin by the catechol moiety and its subsequent acquisition by bacteria. By contrast, selective $\beta_{1}$ blockade may decrease the concentrations of circulating and tissue inflammatory cytokines, may inhibit bacterial growth, and may improve fibrinolysis [20]. In patients with decompensated heart failure, levosimendan reduced significantly circulating levels of proinflammatory cytokines (IL-6, TNF $\alpha$, and TNF $\alpha /$ IL-10 ratio) and soluble apoptosis mediators (soluble Fas and Fas ligand), partly as a result of improved haemodynamics [78]. Vasopressin decreased plasma cytokines more than norepinephrine [79], especially in patients with less severe shock and vasopressin has other complex immune effects [80]. Selepressin-induced reduction of IL- 6 and nitrite/nitrate levels may limit vascular permeability associated with vasodilatory shock [15].

\section{Effects on survival}

The extent to which vasoactive drugs can improve haemodynamic parameters in shock is influenced by the choice, dose and timing of individual and/or combinations of agents. Unfortunately, a definitive survival benefit for the commonest agents administered is lacking. A Cochrane review of high quality randomised trials found no survival advantage related to the choice of the vasoactive drugs [81]. Accordingly, recommendations are made based on organ dysfunction effects and safety issues, not survival benefits [2].

\section{Septic shock}

Norepinephrine is the recommended first-line vasoactive drug [2]. Epinephrine, phenylephrine and vasopressin are usually considered second-line agents, with dopamine reserved for bradycardic patients [2]. Norepinephrine and epinephrine achieve similar shock reversal and no randomised trial demonstrates survival advantage when using one agent over the other [81]. Likewise, 28-day survival when combining norepinephrine and dobutamine is similar to epinephrine alone [33]. Notably, kidney failure-free days and mortality were not different in the VANISH trial comparing early vasopressin versus norepinephrine [82]. The addition of low-dose vasopressin to norepinephrine did not improve survival in a large, double-blind trial of vasopressor-dependent shock, although a potential benefit for patients with less severe shock (norepinephrine $<15 \mu \mathrm{g} / \mathrm{min}$ ) was not excluded [83]. In this trial, there was a synergic effect of vasopressin and hydrocortisone on survival [84]. However, these beneficial effects were not confirmed in the VANISH trial [82]. Similarly, there are no large-scale trials with mortality as the primary outcome comparing norepinephrine and either phenylephrine or other V1a agonists such as terlipressin or selepressin. Finally, a large blinded trial comparing norepinephrine versus dopamine in generalised shock (SOAP II) reported an increase in arrhythmic events with dopamine as first-line therapy, but no difference in survival either overall (primary endpoint) or in the pre-defined sub-group with septic shock [85]. Moreover, mortality rates increased during a 6 month period of norepinephrine shortage in 26 US hospitals (during that period norepinephrine was mostly replaced by phenylephrine and dopamine) [86].

Inotropes such as dobutamine and levosimendan have also been suggested as second-line agents for the management of refractory shock [2]. A network metaanalysis of 33 randomised trials of vasoactive agents in septic shock reported that levosimendan, dobutamine, epinephrine, vasopressin and norepinephrine with dobutamine were all significantly associated with survival, with levosimendan and dobutamine affording the greatest benefit [87]. In contrast, a multicentre, doubleblind trial in vasopressor-dependent shock reported increased arrhythmias and ventilator weaning difficulties with levosimendan (versus placebo) and no difference in survival [49]. In this trial the randomization was not stratified according to the presence or absence of left ventricular dysfunction [49]. A small $(n=77)$ singlecentre trial reported decreased mortality with esmolol in selected septic shock patients [41]. Interestingly, drugs 
with positive chronotropic effects may be associated with higher risk of death than those without or with negative chronotropic effects (Fig. 2).

\section{Other forms of shock}

In other forms of distributive shock provoked by anaphylaxis or pancreatitis, there is a paucity of high quality evidence and randomised trials examining the effect of vasoactive agents on survival. Synthetic human angiotensin II has recently been reported to improve MAP in a multicentre, double-blind trial of vasodilatory shock due to a variety of causes and refractory to traditional vasoactive drugs [25]. However, caution is advised in low cardiac output shock. A non-significant trend to improved survival (secondary outcome) was also noted.
Vasopressin (up to $0.06 \mathrm{U} / \mathrm{min}$ ) and early methylene blue administration may also improve survival in vasoplegic shock post-cardiac surgery $[45,88]$.

Despite the widespread utilization of vasoactive drugs in cardiogenic shock, there is a paucity of evidence to guide selection. The SOAP II trial reported a statistically significant higher risk of mortality with dopamine compared to norepinephrine in the pre-defined sub-group of patients with cardiogenic shock [85]. Despite being the largest randomised trial to date supporting norepinephrine in cardiogenic shock, some have raised questions regarding the widespread validity of its results [36]. Norepinephrine is associated with fewer arrhythmias and based on current data is likely the vasoactive drug of choice for most patients with cardiogenic shock [36].

$\mathbf{a}$

Risk of death with drugs with no or negative chronotropic effects

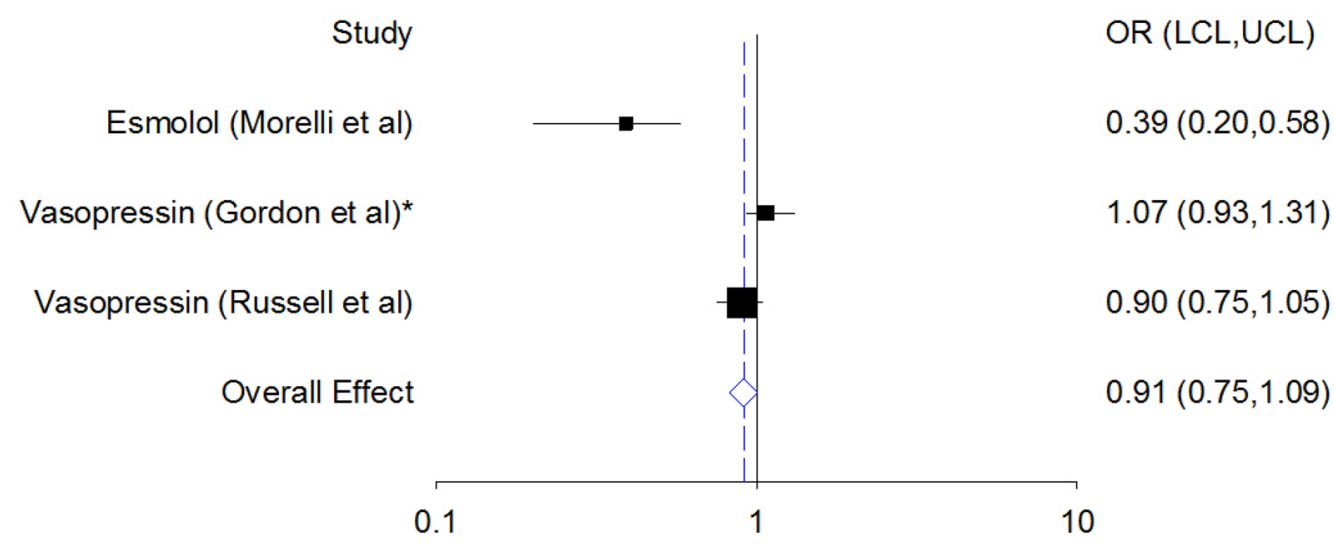

b

Risk of death with drugs with positive chronotropic effects

Study
Dopamine (Patel et al)
Levosimendan (Gordon et al)
Epinephrine (Annane et al)
Dopamine (DeBacker et al)
Overall Effect

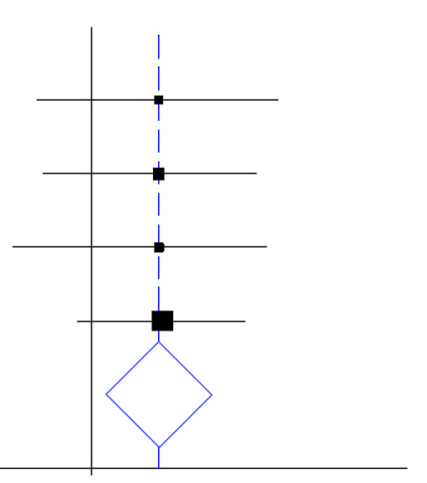

$\mathrm{OR}(\mathrm{LCL}, \mathrm{UCL})$

$1.16(0.90,1.44)$

$1.16(0.84,1.47)$

$1.17(0.97,1.40)$

$1.16(0.90,1.40)$

1

Fig. 2 Potential interaction with drugs associated chronotropic effects and mortality in septic shock trials. Forrest plots of sepsis trials stratified according to drugs associated with no or negative chronotropic effects (panel A) or with positive chronotropic effects (panel B). Drugs that lowered or kept heart rate constant were associated with an odds ratio of dying of less than 1 with the $95 \%$ confidence interval including no effect or harm (panel A). Drugs that induced tachycardia were associated with an odds ratio of dying of more than 1 with the 95\% confidence interval including no effect or benefit (panel B) 
Additional considerations such as the cause or presentation type of cardiogenic shock may also influence vasoactive drug selection. Routine use of inotropes in patients with heart failure has been associated with increased mortality [89]. However, in patients with cardiogenic shock, inotropes are utilised for haemodynamic support and have an important role in optimising perfusion to vital organs [90]. Dobutamine and milrinone both improve inotropy that increases cardiac output. Both agents are associated with arrhythmias and systemic hypotension. Studies comparing these two agents suggest similar clinical outcomes although milrinone has a longer half-life and is associated with more profound hypotension [91].

Haemorrhagic shock is the most common type of shock seen with trauma [92]. The therapeutic goals are restoration of blood volume and definitive control of bleeding [93]. Vasoactive drugs can be transiently utilised in the presence of life-threatening hypotension [94]. The impact of vasoactive drugs on trauma outcome is poorly understood. Animal studies and a small clinical trial suggest that vasopressin in conjunction with rapid haemorrhage control may improve blood pressure without causing increased blood loss, leading to improved outcomes [95-97]. However, observational studies have shown that vasoactive drug use in general is an independently associated with increased mortality in trauma patients [98-100].

\section{Practical use}

In routine, physicians should consider as much as possible to individualize the use of vasoactive drugs taking into account patient's comorbidities and physiological characteristics, the aetiology of shock, the local environement and their own experiences with the various vasoactive drugs available on the market.

\section{Choice of vasoactive drugs}

After adequate fluid resuscitation and assessment, determining vasoactive drug choice depends upon the aetiology and pathophysiology of the hypotensive episode (Fig. 3). In hypovolaemic, cardiogenic and obstructive shock, hypotension results from decreased CO. In these types of shock, regional perfusion may correlate with global perfusion [100]. However, distributive shock (sepsis, pancreatitis etc.) is more complicated with vasoplegia, shunting, decreased oxygen extraction and low, normal or high $\mathrm{CO}$.

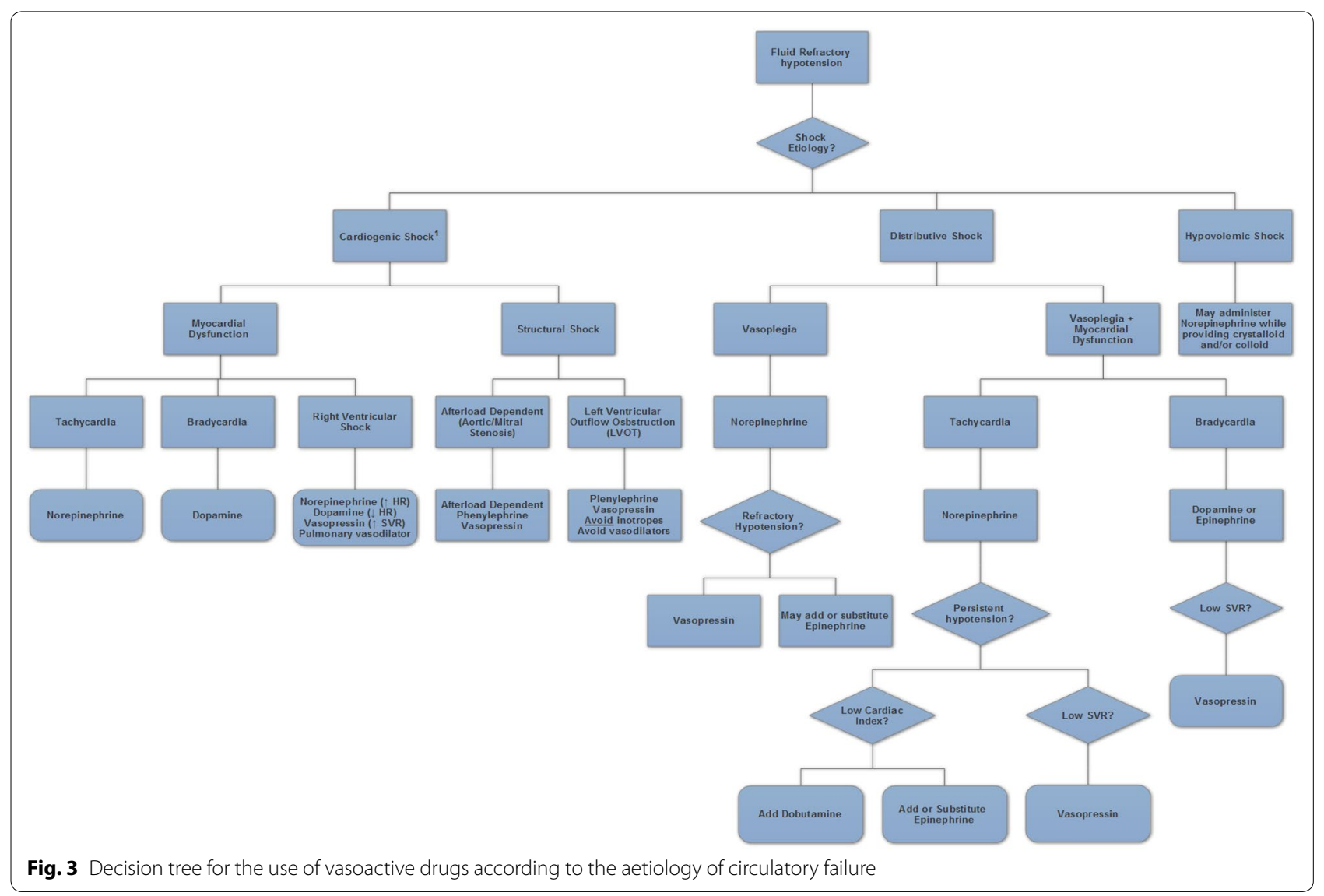


In fluid-refractory hypotension, vasoactive agents are indicated and may be initiated during fluid resuscitation, and subsequently weaned as tolerated [26]. Ultrasound, when possible, can help ascertain shock aetiology and/or assist continued management.

In cardiogenic shock, decreased $\mathrm{CO}$ aetiology is generally due to poor myocardial function. Individualized MAP goals are required as the hypoperfusion risk is balanced against the potential negative impact on $\mathrm{CO}$, myocardial oxygen consumption, ischaemia and dysrhythmias. In acute heart failure (excluding pre-revascularisation myocardial infarction), guidelines recommend inotropes (dobutamine, dopamine, phosphodiesterase III inhibitors) as the first line agent $[35,101]$. In persistently hypotensive cardiogenic shock with tachycardia, norepinephrine is advised $[35,101]$ and in patients with bradycardia, dopamine may be considered [36]. In specific afterload dependent states (aortic stenosis, mitral stenosis), phenylephrine or vasopressin is advised [36].

In distributive shock, norepinephrine is recommended as the initial vasoactive drug after appropriate fluid resuscitation [2, 102]. If hypotension persists, vasopressin (up to $0.03 \mathrm{UI} / \mathrm{min}$ ) should be considered for reducing norepinephrine [83] and possibly renal replacement therapy requirements [82].

Myocardial depression is common in septic shock [103]. Persistent hypotension with evidence of myocardial depression and decreased perfusion may benefit from inotropic therapy by adding dobutamine to norepinephrine or using epinephrine as a single agent. Dopamine is only recommended in hypotensive patients with bradycardia or low risk for tachycardia [2, 35, 104]. Phenylephrine should be reserved for salvage therapy.

Uncertainty surrounding the optimal use of levosimendan exists and should be clarified prior to including it in standardized treatment guidelines. Likewise, $\beta_{1}$ antagonists cannot be recommended while we await for their evaluation in a multicentre trial (https://doi. org/10.1186/ISRCTN12600919).

\section{Therapeutic targets}

Haemodynamic support should optimise perfusion to vital organs ensuring adequate cellular delivery of oxygen. Vasoactive drugs titrated to specific targets reflect optimal end-organ perfusion (e.g., urinary output, serum lactate clearance). Mean arterial pressure reflects tissue perfusion. Specific organs have different tolerance to hypotension based on their ability to autoregulate blood flow. However, there is a threshold MAP where tissue perfusion may be linearly dependent on blood pressure. Current guidelines recommend that vasopressors be titrated to maintain a MAP of $65 \mathrm{~mm} \mathrm{Hg}$ in the early resuscitation of septic shock [2]. However, the optimal MAP target for patient with shock is still a point of debate. Small studies targeting higher MAPs (85 versus $65 \mathrm{~mm} \mathrm{Hg}$ ) were associated with higher cardiac index but no significant change in other measurements of global and regional perfusion $[105,106]$. A multicentre trial compared vasopressor titration to MAP of 65-70 versus $80-85 \mathrm{~mm} \mathrm{Hg}$ on mortality in patients with septic shock [107]. Although no mortality difference was reported ( 28 or 90 days), the higher target $(80-85 \mathrm{~mm}$ $\mathrm{Hg}$ ) was associated with more arrhythmias. In patients with documented chronic hypertension, the higher target MAP (80-85 $\mathrm{mm} \mathrm{Hg}$ ) was associated with decreased renal replacement therapy. Patients 75 years or older, may benefit from lower rather than higher target (MAP 60-65 vs $75-80 \mathrm{~mm} \mathrm{Hg}$ ). These finding suggests that although $65 \mathrm{~mm} \mathrm{Hg}$ may be a good starting target for most patients, clinicians may need to individualize the target based on specific patient history and findings.

Inotropes should be titrated with concomitant measurements of $\mathrm{CO}$ and tissue perfusion. Targeting supraphysiologic cardiac output does not improve outcomes and should be avoided [108]. Clinicians should complement haemodynamic targets with other serial markers of systemic and organ perfusion, such as lactate, mixed or central venous oxygen saturations, urine output, skin perfusion, renal and liver function tests, mental status and other haemodynamic variables. Elevated lactate has been shown to correlate with increased mortality in various types of shock. Although lactate does not increase solely because of poor tissue perfusion it can be utilised as a marker of the adequacy of haemodynamic support. Lactate guided resuscitation has been consistently shown to be effective $[109,110]$.

\section{Monitoring and weaning}

Administration of vasoactive agents should always be targeted to effect and not based on a fixed dose (but a maximal dose may be considered for some agents, e.g., vasopressin or angiotensin). Vasoactive drugs should target a precise blood pressure level using intra-arterial monitoring. As inotropes and vasopressors impact cardiac function and tissue perfusion, $\mathrm{CO}$ monitoring is desired primarily using echocardiographic evaluations and measurements of blood lactate and mixed-venous or central venous $\mathrm{O}_{2}$ saturation at regular intervals. However, some patient populations may benefit from pulmonary artery catheter or pulse wave analysis with or without calibration [111, 112].

The importance of vasoactive agent de-escalation is comparable to the indication for initiation [26]. Physicians and nurses may maintain a higher blood pressure than desired or continue a supra-therapeutic dose of inotropes, as they overestimate the risk of re-aggravation. 
We suggest that weaning of vasoactive drugs should be performed as soon as haemodynamic stabilisation is achieved. Computerised assisted weaning may reduce unnecessary exposure to vasoactive drugs [113].

The sequence of withdrawal of vasopressin is usually after weaning of norepinephrine, as performed in VASST and VANISH, as withdrawing vasopressin first was associated with more haemodynamic instability $[114,115]$.

\section{Serious adverse events}

Arrhythmias are the most frequent complications of vasoactive drugs, ranging from $2-25 \% .2-15 \%$ with norepinephrine [33, 82-84], about $15 \%$ with epinephrine $[33,34]$, up to $25 \%$ with dopamine [85], about $1-2 \%$ with vasopressin $[82,83]$, about $6 \%$ with synthetic human angiotensin II [25], up to $25 \%$ with dobutamine [108], and about $6 \%$ with levosimendan [49] (Table 2). The risk of arrhythmias may be lower with norepinephrine and vasopressin than with dopamine, epinephrine, dobutamine, or levosimendan. In a multinational prospective cohort study, treatment with catecholamines was the main trigger of life-threatening arrhythmias in ICU patients, which were independently associated with hospital mortality and neurological sequelae [116]. The prevalence of arrhythmias may be higher when catecholamines are titrated toward MAP values of 80-85 [107].

Acute coronary events occurred in $1-4 \%$ of research participants, a prevalence that was consistent across trials (and between groups) investigating catecholamines, vasopressin, angiotensin II or levosimendan $(33,34,49$, $82-84)$. The prevalence of stroke, limb ischemia, and intestinal ischemia was $0.3-1.5,2$, and $0.6-4 \%$ [33, 82, 83]. Central nervous bleeding was reported in roughly $1 \%$ of catecholamine-treated septic shock [33]. These serious cerebrovascular complications are more likely to occur

Table 2 Main serious adverse reactions associated with vasoactive drugs

\begin{tabular}{|c|c|c|c|c|c|c|c|}
\hline \multirow[t]{2}{*}{ Molecules } & \multicolumn{2}{|l|}{ Arrhythmias } & \multicolumn{4}{|l|}{ Vascular } & \multirow[t]{2}{*}{ Metabolic } \\
\hline & Supra-ventricular & Ventricular & $\begin{array}{l}\text { Myocardial } \\
\text { ischemia }\end{array}$ & Stroke & limbs & $\begin{array}{l}\text { Other tissues/ } \\
\text { organs }\end{array}$ & \\
\hline Dopamine & $\begin{array}{l}\text { Atrial fibrillation; } \\
\text { multifocal atrial } \\
\text { tachycardia; car- } \\
\text { diac conduction } \\
\text { abnormalities }\end{array}$ & $\begin{array}{l}\text { Ventricular tachy- } \\
\text { cardia/fibrillation }\end{array}$ & + & + & + & + & Not described \\
\hline Dobutamine & $\begin{array}{l}\text { Atrial fibrillation; } \\
\text { multifocal atrial } \\
\text { tachycardia, }\end{array}$ & $\begin{array}{l}\text { Ventricular tachy- } \\
\text { cardia/fibrillation }\end{array}$ & + & Not described & Not described & Not described & Hypokalemia \\
\hline Epinephrine $^{a}$ & $\begin{array}{l}\text { Atrial fibrillation; } \\
\text { multifocal atrial } \\
\text { tachycardia, }\end{array}$ & $\begin{array}{l}\text { Ventricular tachy- } \\
\text { cardia/fibrillation }\end{array}$ & +++ & + & + & + & $\begin{array}{l}\text { Lactic acidosis; } \\
\text { hyperglycaemia; } \\
\text { hypoglycaemia; } \\
\text { insulin resistance; } \\
\text { hypokalemia; }\end{array}$ \\
\hline Norepinephrine & $\begin{array}{l}\text { Atrial fibrillation; } \\
\text { multifocal atrial } \\
\text { atchycardia, } \\
\text { bradycardia }\end{array}$ & $\begin{array}{l}\text { Ventricular tachy- } \\
\text { cardia/fibrillation }\end{array}$ & ++ & + & + & + & Not described \\
\hline Vasopressin & $\begin{array}{l}\text { Atrial fibrilation; } \\
\text { bradycardia }\end{array}$ & $\begin{array}{l}\text { Ventricular tachy- } \\
\text { cardia/fibrillation }\end{array}$ & ++ & + & + & + & hyponatremia \\
\hline Angiotensin $\|^{\mathrm{b}}$ & \pm & $\begin{array}{l}\text { Ventricular tachy- } \\
\text { cardia }\end{array}$ & Not described & Not described & + & Not described & Not described \\
\hline Levosimendan & $\begin{array}{l}\text { Atrial fibrillation; } \\
\text { multifocal atrial } \\
\text { tachycardia; } \\
\text { junctional tachy- } \\
\text { cardia }\end{array}$ & $\begin{array}{l}\text { Ventricular tachy- } \\
\text { cardia/fibrilation }\end{array}$ & Not described & Not described & Not described & Not described & $\begin{array}{l}\text { Metabolic alkalosis; } \\
\text { hypokalemia }\end{array}$ \\
\hline $\begin{array}{l}\text { Esmolol/ } \\
\text { Landiolol }\end{array}$ & $\begin{array}{l}\text { Bradycardia; } \\
\text { conduction } \\
\text { abnormalities; } \\
\text { sinus arrest; } \\
\text { asystole }\end{array}$ & & + & Not described & + & Not described & $\begin{array}{l}\text { Hyperkalemia; met- } \\
\text { abolic acidosis }\end{array}$ \\
\hline
\end{tabular}

\footnotetext{
${ }^{a}$ Epinephrine my also be associated with brain haemorrhage

b Synthetic human angiotensin II
} 
with rapid variations in the infusion rate of vasoactive drugs, and in patients with coagulation disorders.

Catecholamine infusion was associated with for onethird of all cases of drug-induced Takotsubo cardiomyopathy in a recent systematic review of the literature [117]. $\beta_{2}$ adrenergic receptors agonists may aggravate lactic acidosis and ICU-acquired hyperglycaemia.

\begin{abstract}
Author details
1 General ICU, Raymond Poincaré Hospital (APHP), School of Medicine Simone Veil U1173 Laboratory of Infection and Inflammation (University of Versailles SQY, University Paris Saclay/INSERM), CRICS-TRIGERSEP Network (F-CRIN), 104 boulevard Raymond Poincaré, 92380 Garches, France. ${ }^{2}$ Intensive Care Unit, CHU F. Bourguiba, Monastir, Tunisia. ${ }^{3}$ Department of Intensive Care, CHIREC Hospitals, Université Libre de Bruxelles, Brussels, Belgium. ${ }^{4}$ Medical ICU, Peking Union Medical College Hospital, 1 Shuai Fu Yuan, 100730 Beijing, China. ${ }^{5}$ Section of Anaesthetics, Pain Medicine and Intensive Care, Imperial College London, London, UK. ${ }^{6}$ Departamento de Medicina Intensiva, Facultad de Medicina, Pontificia Universidad Católica de Chile, Santiago, Chile. ${ }^{7}$ UAMS College of Pharmacy, Little Rock, AR, USA. ${ }^{8}$ Section of Acute Care Surgical Services, Surgical/Trauma Critical Care, Barnes Jewish Hospital, St. Louis, MI, USA. ${ }^{9}$ Department of Intensive Care, The Queen Elizabeth Hospital School of Medicine, University of Adelaide, Adelaide, SA, Australia. ${ }^{10}$ School of Epidemiology and Preventive Medicine, Monash University, Victoria, Australia ${ }^{11}$ Centre for Heart Lung Innovation, St. Paul's Hospital, University of British Columbia, 1081 Burrard Street, Vancouver, BC, Canada. ${ }^{12}$ Sound Critical Care, Sound Physicians, Houston, TX, USA.
\end{abstract}

\section{Acknowledgements}

ACG is funded by an NIHR Research Professorship award (RP-2015-06-018).

\section{Compliance with ethical standards}

\section{Conflicts of interest}

DA reports having received a grant from the French Ministry of Health to conduct a trial comparing epinephrine to norepinephrine plus dobutamine for septic shock (CATS). DDB reports that he acts as a consultant to and material for studies by Edwards Lifesciences. ACG reports that outside of this work he has received speaker fees from Orion Corporation Orion Pharma and Amomed Pharma. He has consulted for Ferring Pharmaceuticals, Tenax Therapeutics, Baxter Healthcare, Bristol-Myers Squibb and GSK, and received grant support from Orion Corporation Orion Pharma, Tenax Therapeutics and HCA International with funds paid to his institution. GH reports no financial conflict of interest. $J R$ reports patents owned by the University of British Columbia (UBC) that are related to PCSK9 inhibitor(s) and sepsis and related to the use of vasopressin in septic shock. JR is an inventor on these patents. JR is a founder, Director and shareholder in Cyon Therapeutics Inc. (developing a sepsis therapy (PCSK9 inhibitor)). JR has share options in Leading Biosciences Inc. JR is a shareholder in Molecular You Corp. JR reports receiving consulting fees in the last 3 years from: (1) Asahi Kesai Pharmaceuticals of America (AKPA)(developing recombinant thrombomodulin in sepsis). (2) La Jolla Pharmaceuticals (developing angiotensin II; JR chaired the DSMB of a trial of angiotensin II from 2015 to 2017)_no longer actively consulting. (3) Ferring Pharmaceuticals (manufactures vasopressin and was developing selepressin) — no longer actively consulting. (4) Cubist Pharmaceuticals (now owned by Merck; formerly Trius Pharmaceuticals; developing antibiotics) — no longer 3 actively consulting. (5) Leading Biosciences (was developing a sepsis therapeutic that is no longer in development) —no longer actively consulting. (6) Grifols (sells albumin)—no longer actively consulting. (7) CytoVale Inc. (developing a sepsis diagnostic) — no longer actively consulting. JR reports having received an investigator-initiated grant from Grifols (entitled "Is HBP a mechanism of albumin's efficacy in human septic shock?") that is provided to and administered by UBC.

Received: 20 March 2018 Accepted: 22 May 2018

Published online: 4 June 2018

\section{References}

1. Goodman and Gilman's (2011) Pharmacological Basis of Therapeutics Twelfth (ed). New York

2. Rhodes A, Evans LE, Alhazzani W et al (2017) Surviving sepsis campaign: international guidelines for the management of sepsis and septic shock: 2016. Intensive Care Med 43:304-377

3. Aguilera G, Rabadan-Diehl C (2000) Vasopressinergic regulation of the hypothalamic-pituitary-adrenal axis: implications for stress adaptation. Regul Pept 96(1-2):23-29

4. Yamamoto K, Ikeda U, Okada K et al (1997) Arginine vasopressin increases nitric oxide synthesis in cytokine-stimulated rat cardiac myocytes. Hypertension 30(5):1112-1120

5. Rudichenko VM, Beierwaltes WH (1995) Arginine vasopressin-induced renal vasodilation mediated by nitric oxide. J Vasc Res 32(2):100-105

6. Landry DW, Levin HR, Gallant EM et al (1997) Vasopressin deficiency contributes to the vasodilation of septic shock. Circulation 95(5):1122-1125

7. Landry DW, Levin HR, Gallant EM et al (1997) Vasopressin pressor hypersensitivity in vasodilatory septic shock. Crit Care Med 25(8):1279-1282

8. Holmes CL, Walley KR, Chittock DR, Lehman T, Russell JA (2001) The effects of vasopressin on hemodynamics and renal function in severe septic shock: a case series. Intensive Care Med 27(8):1416-1421

9. Malay MB, Ashton RC Jr, Landry DW, Townsend RN (1999) Low-dose vasopressin in the treatment of vasodilatory septic shock. J Trauma 47(4):699-703

10. Patel BM, Chittock DR, Russell JA, Walley KR (2002) Beneficial effects of short-term vasopressin infusion during severe septic shock. Anesthesiology 96(3):576-582

11. Siami S, Polito A, Porcher R et al (2013) Thirst perception and osmoregulation of vasopressin secretion are altered during recovery from septic shock. PLoS One 8(11):e80190

12. Boucheix OB, Milano SP, Henriksson M, Reinheimer TM (2013) Selepressin, a new V1A receptor agonist: hemodynamic comparison to vasopressin in dogs. Shock 39(6):533-538

13. Asfar P, Russell JA, Tuckermann J, Radermacher P (2016) Selepressin in septic shock: a step toward decatecholaminization? Crit Care Med 44(1):234-236

14. Russell JA, Vincent JL, Kjolbye AL et al (2017) Selepressin, a novel selective vasopressin V1A agonist, is an effective substitute for norepinephrine in a phase lla randomized, placebo-controlled trial in septic shock patients. Crit Care 21(1):213

15. He X, Su F, Taccone FS, Laporte $R$ et al (2016) A selective V(1A) receptor agonist, selepressin, is superior to arginine vasopressin and to norepinephrine in ovine septic shock. Crit Care Med 44(1):23-31

16. Maybauer MO, Maybauer DM, Enkhbaatar P et al (2014) The selective vasopressin type 1a receptor agonist selepressin (FE 202158) blocks vascular leak in ovine severe sepsis*. Crit Care Med 42(7):e525-e533

17. Farmakis D, Alvarez J, Gal TB et al (2016) Levosimendan beyond inotropy and acute heart failure: evidence of pleiotropic effects on the heart and other organs: an expert panel position paper. Int J Cardiol 222:303-312

18. Annane D, Bellissant E, Cavaillon JM (2005) Septic shock. Lancet 365(9453):63-78

19. Boldt J, Menges T, Kuhn D, Diridis C, Hempelmann G (1995) Alterations in circulating vasoactive substances in the critically ill-a comparison between survivors and non-survivors. Intensive Care Med 21(3):218-225

20. de Montmollin E, Aboab J, Mansart A, Annane D (2009) Bench-to-bedside review: beta-adrenergic modulation in sepsis. Crit Care 13(5):230

21. Reynolds RD, Gorczynski RJ, Quon CY (1986) Pharmacology and pharmacokinetics of esmolol. J Clin Pharmacol 26(suppl A):A3-A14

22. Atarashi $\mathrm{H}$, Kuruma A, Yashima M et al (2000) Pharmacokinetics of landiolol hydrochloride, a new ultra-short-acting beta-blocker, in patients with cardiac arrhythmias. Clin Pharmacol Ther 68(2):143-150

23. Page IH, Helmer OM (1940) A crystalline pressor substance (Angiotonin) resulting form the reaction between renin and renin-activator. J Exp Med 71(1):29-42

24. Rajagopalan S, Kurz S, Münzel T et al (1996) Angiotensin II-mediated hypertension in the rat increases vascular superoxide production via membrane NADH/NADPH oxidase activation. Contribution to alterations of vasomotor tone. J Clin Invest 97(8):1916-1923 
25. Khanna A, English SW, Wang XS et al (2017) Angiotensin II for the treatment of vasodilatory shock. N Engl J Med 377:419-430

26. Vincent JL, De Backer D (2013) Circulatory shock. N Engl J Med 369(18):1726-1734

27. Perez P, Kimmoun A, Blime V, Levy B (2014) Increasing mean arterial pressure in cardiogenic shock secondary to myocardial infarction: effects on hemodynamics and tissue oxygenation. Shock 41(4):269-274

28. Maas JJ, Pinsky MR, de Wilde RB, de Jonge E, Jansen JR (2013) Cardiac output response to norepinephrine in postoperative cardiac surgery patients: interpretation with venous return and cardiac function curves. Crit Care Med 41(1):143-150

29. Levy B, Perez P, Perny J, Thivilier C, Gerard A (2011) Comparison of norepinephrine-dobutamine to epinephrine for hemodynamics, lactate metabolism, and organ function variables in cardiogenic shock. A prospective, randomized pilot study. Crit Care Med 39(3):450-455

30. Guinot PG, Longrois D, Kamel S, Lorne E, Dupont H (2018) Ventriculoarterial coupling analysis predicts the hemodynamic response to norepinephrine in hypotensive postoperative patients: a prospective observational study. Crit Care Med 46(1):e17-e25

31. Vieillard-Baron A, Caille V, Charron C, Belliard G, Page B, Jardin F (2008) Actual incidence of global left ventricular hypokinesia in adult septic shock. Crit Care Med. 36(6):1701-1706

32. Sun D, Huang A, Mital S et al (2002) Norepinephrine elicits beta2-receptor-mediated dilation of isolated human coronary arterioles. Circulation 106(5):550-555

33. Annane D, Vignon P, Renault A et al (2007) Norepinephrine plus dobutamine versus epinephrine alone for management of septic shock: a randomised trial. Lancet 370(9588):676-684

34. Myburgh JA, Higgins A, Jovanovska A, Lipman J, Ramakrishnan N, Santamaria J, CAT Study investigators (2008) A comparison of epinephrine and norepinephrine in critically ill patients. Intensive Care Med 34(12):2226-2234

35. Marik PE, Mohedin M (1994) The contrasting effects of dopamine and norepinephrine on systemic and splanchnic oxygen utilization in hyperdynamic sepsis. JAMA 272(17):1354-1357

36. van Diepen S, Katz JN, Albert NM et al (2017) Contemporary management of cardiogenic shock: a scientific statement from the American heart association. Circulation 136(16):e232-e268

37. Mon W, Stewart A, Fernando R et al (2017) Cardiac output changes with phenylephrine and ephedrine infusions during spinal anesthesia for cesarean section: a randomized, double-blind trial. J Clin Anesth $37: 43-48$

38. Wasilewski MA, Grisanti LA, Song J et al (2016) Vasopressin type 1A receptor deletion enhances cardiac contractility, $\beta$-adrenergic receptor sensitivity and acute cardiac injury-induced dysfunction. Clin Sci 130(22):2017-2027. https://doi.org/10.1042/CS20160363

39. Bouferrache K, Amiel JB, Chimot L et al (2012) Initial resuscitation guided by the surviving sepsis campaign recommendations and early echocardiographic assessment of hemodynamics in intensive care unit septic patients: a pilot study. Crit Care Med 40(10):2821-2827

40. Schumann J, Henrich EC, Strobl H et al. (2018) Inotropic agents and vasodilator strategies for the treatment of cardiogenic shock or low cardiac output syndrome. Cochrane Database of Systematic Reviews. Issue 1, Art. No.: CD009669

41. Morelli A, Ertmer C, Westphal M et al (2013) Effect of heart rate contro with esmolol on hemodynamic and clinical outcomes in patients with septic shock: a randomized clinical trial. JAMA 310(16):1683-1691

42. Aviado DM Jr, Schmidt CF (1957) Effects of sympathomimetic drugs on pulmonary circulation: with special reference to a new pulmonary vasodilator. J Pharmacol Exp Ther 120(4):512-527

43. Monnet X, Jabot J, Maizel J, Richard C, Teboul JL (2011) Norepinephrine increases cardiac preload and reduces preload dependency assessed by passive leg raising in septic shock patients. Crit Care Med 39(4):689-694

44. Persichini R, Silva S, Teboul JL et al (2012) Effects of norepinephrine on mean systemic pressure and venous return in human septic shock. Crit Care Med 40(12):3146-3153

45. Hajjar LA, Vincent JL, Barbosa Gomes Galas FR et al (2017) Vasopressin versus norepinephrine in patients with vasoplegic shock after cardiac surgery: the vancs randomized controlled trial. Anesthesiology 126(1):85-93
46. James A, Amour J (2018) Vasopressin versus norepinephrine in patients with vasoplegic shock after cardiac surgery: a discussion of the level of evidence. Anesthesiology 128(1):228

47. Cheng Y, Pan T, Ge M, et al. (2018) Evaluation of vasopressin for vasoplegic shock in patients with preoperative left ventricular dysfunction after cardiac surgery: a propensity-score analysis. Shock. Feb 7. 10.1097/ shk.0000000000001114

48. Lewis RJ, Angus DC, Laterre PF et al (2018) Rationale and design of an adaptive phase $2 \mathrm{~b} / 3$ clinical trial of selepressin for adults in septic shock, Selepressin evaluation program for sepsis-induced shock-adaptive clinical trial. Ann Am Thorac Soc 15(2):250-257

49. Gordon AC, Perkins GD, Singer M et al (2016) Levosimendan for the prevention of acute organ dysfunction in sepsis. N Engl J Med 375(17):1638-1648

50. De Backer D, Creteur J, Noordally O, Smail N, Gulbis B, Vincent JL (1998) Does hepato-splanchnic $\mathrm{VO}_{2} / \mathrm{D} \mathrm{O}_{2}$ dependency exist in critically ill septic patients? Am J Respir Crit Care Med 157:1219-1225

51. Hernandez G, Bruhn A, Luengo C et al (2013) Effects of dobutamine on systemic, regional and microcirculatory perfusion parameters in septic shock: a randomized, placebo-controlled, double-blind, crossover study. Intensive Care Med 39:1435-1443

52. De Backer D, Creteur J, Silva E, Vincent JL (2003) Effects of dopamine, norepinephrine, and epinephrine on the splanchnic circulation in septic shock: which is best? Crit Care Med 31:1659-1667

53. van Haren FM, Rozendaal FW, van der Hoeven JG (2003) The effect of vasopressin on gastric perfusion in catecholamine-dependent patients in septic shock. Chest 124:2256-2260

54. Georger JF, Hamzaoui O, Chaari A, Maizel J, Richard C, Teboul JL (2010) Restoring arterial pressure with norepinephrine improves muscle tissue oxygenation assessed by near-infrared spectroscopy in severely hypotensive septic patients. Intensive Care Med 36:1882-1889

55. Boerma EC, Ince C (2010) The role of vasoactive agents in the resuscitation of microvascular perfusion and tissue oxygenation in critically ill patients. Intensive Care Med 36:2004-2018

56. Jhanji S, Stirling S, Patel N, Hinds CJ, Pearse RM (2009) The effect of increasing doses of norepinephrine on tissue oxygenation and microvascular flow in patients with septic shock. Crit Care Med 37:1961-1966

57. Dubin A, Pozo MO, Casabella CA et al (2009) Increasing arterial blood pressure with norepinephrine does not improve microcirculatory blood flow: a prospective study. Crit Care 13:R92

58. Thooft A, Favory R, Salgado DR et al (2011) Effects of changes in arterial pressure on organ perfusion during septic shock. Crit Care 15:R222

59. Morelli A, Ertmer C, Rehberg S et al (2008) Phenylephrine versus norepinephrine for initial hemodynamic support of patients with septic shock: a randomized, controlled trial. Crit Care 12:R143

60. Morelli A, Lange M, Ertmer C et al (2008) Short-term effects of phenylephrine on systemic and regional hemodynamics in patients with septic shock: a crossover pilot study. Shock 29:446-451

61. Dubois MJ, De Backer D, Creteur J, Anane S, Vincent JL (2003) Effect of vasopressin on sublingual microcirculation in a patient with distributive shock. Intensive Care Med 29:1020-1023

62. Nygren A, Thoren A, Ricksten SE (2009) Vasopressin decreases intestinal mucosal perfusion: a clinical study on cardiac surgery patients in vasodilatory shock. Acta Anaesthesiol Scand 53:581-588

63. Boerma EC, van der Voort PHJ, Ince C (2005) Sublingual microcirculatory flow is impaired by the vasopressin- analogue terlipressin in a patient with catecholamine-resistant septic shock. Acta Anaesthesiol Scand 49:1387-1390

64. Asfar P, Bracht H, Radermacher P (2008) Impact of vasopressin analogues on the gut mucosal microcirculation. Best Pract Res Clin Anaesthesiol 22:351-358

65. Morelli A, Donati A, Ertmer C et al (2011) Short-term effects of terlipressin bolus infusion on sublingual microcirculatory blood flow during septic shock. Intensive Care Med 37:963-969

66. Morelli A, Donati A, Ertmer C et al (2011) Effects of vasopressinergic receptor agonists on sublingual microcirculation in norepinephrinedependent septic shock. Crit Care 15:R217

67. Qiu X, Huang Y, Xu J, Qiu H, Yang Y (2014) Effects of terlipressin on microcirculation of small bowel mesentery in rats with endotoxic shock. J Surg Res 188:503-509 
68. De Backer D, Creteur J, Dubois MJ et al (2006) The effects of dobutamine on microcirculatory alterations in patients with septic shock are independent of its systemic effects. Crit Care Med 34:403-408

69. Enrico C, Kanoore Edul VS et al (2012) Systemic and microcirculatory effects of dobutamine in patients with septic shock. J Crit Care 27:630-638

70. Ospina-Tascón GA, García Marin AF, Echeverri GJ et al (1985) Effects of dobutamine on intestinal microvascular blood flow heterogeneity and $\mathrm{O}_{2}$ extraction during septic shock. J Appl Physiol 122:1406-1417

71. Dubin A, Murias G, Sottile JP et al (2007) Effects of levosimendan and dobutamine in experimental acute endotoxemia: a preliminary controlled study. Intensive Care Med 33:485-494

72. Morelli A, Donati A, Ertmer C et al (2010) Levosimendan for resuscitating the microcirculation in patients with septic shock: a randomized controlled study. Crit Care 14:R232

73. Fuchs C, Ertmer C, Rehberg S (2016) Effects of vasodilators on haemodynamic coherence. Best Pract Res Clin Anaesthesiol 30:479-489

74. Webber J, MacDonald A (1993) Metabolic actions of catecholamines in man. Baillière's Clin Endocrinol Metab 7:393-413

75. Van den Berghe $G$, de Zegher $F$ (1996) Anterior pituitary function during critical illness and dopamine treatment. Crit Care Med 24(9):1580-1590

76. Sharshar T, Annane D (2008) Endocrine effects of vasopressin in critically ill patients. Best Pract Res Clin Anesthesiol 22:265-273

77. Bermejo-Martin JF, Andaluz-Ojeda D, Almansa R et al (2016) Defining immunological dysfunction in sepsis: a requisite tool for precision medicine. J Infect 72(5):525-536

78. Parissis JT, Adamopoulos S, Antoniades C et al (2004) Effects of levosimendan on circulating pro-inflammatory cytokines and soluble apoptosis mediators in patients with decompensated advanced heart failure. Am J Cardiol 93(10):1309-1312

79. Russell JA, Fjell C, Hsu JL et al (2013) Vasopressin compared with norepinephrine augments the decline of plasma cytokine levels in septic shock. Am J Resp Crit Care Med 188(3):356-364

80. Russell JA, Walley KR (2010) Vasopressin and its immune effects in septic shock. J Innate Immun 2(5):446-460

81. Gamper G, Havel C, Arrich J et al (2016) Vasopressors for hypotensive shock. Cochrane Database Syst Rev 2:CD003709

82. Gordon AC, Mason AJ, Thirunavukkarusu N et al (2016) Effect of early vasopressin vs norephinephrine on kidney failure patients with septic shock. The Vanish randomised clinical trial. JAMA 316(5):509-518

83. Russell JA, Walley KR, Singer J et al (2008) Vasopressin versus norepinephrine infusion in patients with septic shock. N Engl J Med 358:877-887

84. Russell JA, Walley KR, Gordon AC et al (2009) Interaction of vasopressin infusion, corticosteroid treatment and mortality of septic shock. Crit Care Med 37(3):811-818

85. De Backer D, Biston P, Devriendt J et al (2010) Comparison of dopamine and norepinephrine in the treatment of shock. N Engl J Med 362:779-789

86. Vail E, Gershengorn HB, Hua M, Walkey AJ, Rubenfeld G, Wunsch H (2017) Association Between US norepinephrine shortage and mortality among patients with septic shock. JAMA 317(14):1433-1442

87. Belletti A, Benedetto U, Biondi-Zoccai G et al (2017) The effect of vasoactive drugs on mortality in patients with severe sepsis and septic shock. A network meta-analysis of randomized trials. J Crit Care 37:91-98

88. Mehaffey JH, Johnston LE, Hawkins RB et al (2017) Methylene blue for vasoplegic syndrome after cardiac operation: early administration improves survival. Ann Thorac Surg 104:36-41

89. Elkayam U, Tasissa G, Binanay C et al (2007) Use and impact of inotropes and vasodilator therapy in hospitalized patients with severe heart failure. Am Heart J 153(1):98-104

90. Shah P, Cowger JA (2014) Cardiogenic shock. Crit Care Clin 30(3):391-412

91. Aranda JM Jr, Schofield RB, Pauly DF et al (2003) Comparison of dobutamine versus milrinone therapy in hospitalized patients awaiting cardiac transplantation: a prospective, randomized trial. Am Heart J 145(2):324-329

92. Harris T, Davenport R, Mak M, Brohi K (2018) The evolving science of trauma resuscitation. Emerg Med Clin North Am 36(1):85-106

93. Cannon JW (2018) Hemorrhagic Shock. N Engl J Med 378(4):370-379

94. Rossaint R, Bouillon B, Cerny V et al (2016) The European guideline on management of major bleeding and coagulopathy following trauma: fourth edition. Crit Care 20:100

95. Bayram B, Hocaoglu N, Atilla R, Kalkan S et al (2012) Effects of terlipres$\sin$ in a rat model of severe uncontrolled hemorrhage via liver injury. Am J Emerg Med 30(7):1176-1182

96. Cohn SM, McCarthy J, Stewart RM et al (2011) Impact of low-dose vasopressin on trauma outcome: prospective randomized study. World J Surg 35(2):430-439

97. Westermann I, Dunser MW, Haas T et al (2007) Endogenous vasopressin and copeptin response in multiple trauma patients. Shock 28(6):644-649

98. Hylands M, Toma A, Beaudoin N et al (2017) Early vasopressor use following traumatic injury: a systematic review. BMJ Open 7(11):e017559

99. Plurad DS, Talving P, Lam L et al (2011) Early vasopressor use in critical injury is associated with mortality independent from volume status. J Trauma 71(3):565-570 [discussion 570-572]

100. Sperry JL, Minei JP, Frankel HL (2008) Early use of vasopressors after injury: caution before constriction. J Trauma 64(1):9-14

101. Ponikowski P, Voors AA, Anker SD et al (2016) ESC Guidelines for the diagnosis and treatment of acute and chronic heart failure: the task force for the diagnosis and treatment of acute and chronic heart failure of the European society of cardiology (ESC) Developed with the special contribution of the heart failure association (HFA) of the ESC. Eur Heart J 37(27):2129-2200

102. Excellence NIfHaC (2016) Sepsis : recognition, assessment and early management. In: sepsis: recognition, Assessment and early management. London.

103. Vieillard-Baron A, Caille V, Charron C, Belliard G, Page B, Jardin F (2008) Actual incidence of global left ventricular hypokinesia in adult septic shock. Crit Care Med 36(6):1701-1706

104. Hollenberg SM (2009) Inotrope and vasopressor therapy of septic shock. Crit Care Clin 25(4):781-802 [ix]

105. LeDoux D, Astiz ME, Carpati CM, Rackow EC (2000) Effects of perfusion pressure on tissue perfusion in septic shock. Crit Care Med 28:2729-2732

106. Bourgoin A, Leone M, Delmas A, Garnier F, Albanese J, Martin C (2005) Increasing mean arterial pressure in patients with septic shock: effects on oxygen variables and renal function. Crit Care Med 33:780-786

107. Asfar P, Meziani F, Hamel JF et al (2014) High versus low blood-pressure targets in patients with septic shock. N Engl J Med 370:1583-1593

108. Hayes MA, Timmins AC, Yau EH, Palazzo M, Hinds CJ, Watson D (1994) Elevation of systemic oxygen delivery in the treatment of critically ill patients. N Engl J Med 330(24):1717-1722

109. Jones AE, Shapiro NI, Trzeciak S, Arnold RC, Claremont HA, Kline JA, Emergency Medicine Shock Research Network (EMShockNet) Investigators (2010) Lactate clearance vs central venous oxygen saturation as goals of early sepsis therapy: a randomized clinical trial. JAMA 303(8):739-746

110. Jansen TC, van Bommel J, Schoonderbeek FJ et al (2010) LACTATE study group: early lactate-guided therapy in intensive care unit patients: A multicenter, open-label, randomized controlled trial. Am J Respir Crit Care Med 182:752-761

111. Teboul JL, Saugel B, Cecconi M et al (2016) Less invasive hemodynamic monitoring in critically ill patients. Intensive Care Med 42:1350-1359

112. Cecconi M, De Backer D, Antonelli M et al (2014) Consensus on circulatory shock and hemodynamic monitoring. task force of the European society of intensive care medicine. Intensive Care Med 40:1795-1815

113. Merouani M, Guignard B, Vincent F et al (2008) Norepinephrine weaning in septic shock patients by closed loop control based on fuzzy logic. Crit Care 12:R155 
114. Hammond DA, McCain K, Painter JT et al (2017) Discontinuation of vasopressin before norepinephrine in the recovery phase of septic shock. J Intensive Care Med 2017:885066617714209

115. Bissell BD, Magee C, Moran P, Bastin MLT, Flannery AH (2017) Hemodynamic instability secondary to vasopressin withdrawal in septic shock. Intensive Care Med 2017:885066617716396
116. Annane D, Sébille V, Duboc D et al (1998) Incidence and prognosis of sustained arrhythmias in critically ill patients. Am J Respir Crit Care Med 178(1):20-25

117. Kido K, Guglin M (2017) Drug-induced takotsubo cardiomyopathy. J Cardiovasc Pharmacol Ther 22(6):552-563 